\title{
Donovanose vulvar SOB a FORMA de PSEUdoelefantíase
}

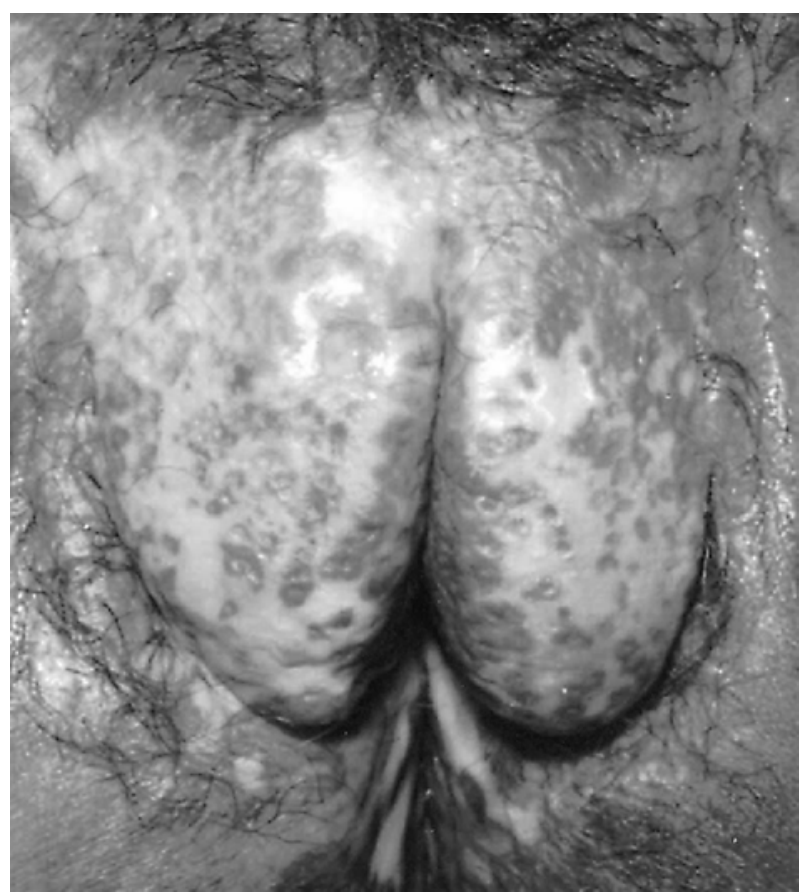

Esta imagem é de uma donovanose vulvar sob a forma crônica de pseudoelefantíase em uma mulher de 29 anos de idade. Ela relatava a doença há dois anos e que, apesar de sua progressão, não procurara recurso médico. Ao exame da genitália externa, extensa lesão vulvar hipertrófica comprometendo grandes e pequenos lábios e monte de vênus, caracterizada por edema, fibrose e pequenas ulcerações, na forma de pseudoelefantíase. Uma biópsia da lesão confirmou o diagnóstico de donovanose pela presença de corpúsculos de Donovan no espécime. Inicialmente, foi tratada com antibióticos, associação de aminoglicosídeo com tetraciclina, sem êxito. Seguiu-se, então, a ressecção cirúrgica de todas as áreas de fibrose, preservando-se o tecido normal, neste caso com cicatrização por segunda intenção, complementada com doxiciclina por 10 dias, com bom resultado cosmético pós-cicatrização.

A donovanose é uma doença infecciosa transmitida sexualmente causada pelo bacilo intracelular Gram-negativo Donovania granulomatis' . É uma doença genital incomum, de localização principalmente vulvar, e a sua progressão para a forma crônica de pseudoelefantíase é extremamente rara. $\bigcirc$ diagnóstico definitivo é baseado na visualização dos corpúsculos de Donovan na amostra de tecido'. O diagnóstico diferencial inclui microfilariose, linfogranuloma venéreo, condiloma gigante e carcinoma. Donovanose e carcinoma da vulva podem coexistir, tendo sido a donovanose considerada uma condição pré-maligna². A pseudoelefantíase resulta da obstrução linfática secundária à resposta inflamatória crônica' e por conter essencialmente tecido fibroso com poucos corpúsculos de Donovan' pouco ou não responde à antibioticoterapia, requerendo ressecção cirúrgica.

\section{Benedito Borges da Silva, Pedro Vitor Costa, Hellena Karine Dias, Simone Maria Batista}

Clínica Ginecológica do Hospital Getúlio Vargas - Universidade federal do Piauí - Teresina - PI

Referências

I. Leung YC, McCartney AJ. Unusual gynaecological presentations of donovanosis as pseudoelephantisiasis and carcinoma of the cervix. Aus NZ Obstet Gynaecol 1990;30: 172-5.

2. Sengupta BS. Vulval cancer follwing or co-existing with cronic granulomatous diseases of vulva. An analysis of its natural history, clinical manifestation and treatment. Trop Doct 1981; I I: I I0- I4. 